\title{
Сравнение радиационной стойкости перспективных биполярных и гетеробиполярных транзисторов
}

\author{
(C) Т.А. Шоболова ${ }^{1}$, А.В. Коротков ${ }^{1}$, Е.В. Петрякова ${ }^{1}$, А.В. Липатников ${ }^{1}$, А.С. Пузанов ${ }^{1}$, \\ С.В. Оболенский 1, , В.А. Козлов ${ }^{2}$ \\ ${ }^{1}$ Нижегородский государственный университет им. Н.И. Лобачевского, \\ 603600 Нижний Новгород, Россия \\ ${ }^{2}$ Институт фризики микроструктур Российской академии наук, \\ 607680 Нижний Новгород, Россия \\ I E-mail: obolensk@rf.unn.ru
}

Поступила в Редакцию 24 апреля 2019 г.

В окончательной редакции 29 апреля 2019 г.

Принята к публикации 29 апреля 2019 г.

\begin{abstract}
Обсуждаются подходы к решению задачи создания эффективных биполярных и гетеробиполярных транзисторов радио- и сверхвысоких частот $(0.1-10$ ГГц), которые могли бы использоваться в качестве активных элементов современных $\mathrm{Si}$ - и GaAs-радиационно стойких аналого-цифровых интегральных схем. Проведено сравнение радиационной стойкости перспективных „латеральных“ Si-биполярных и „вертикальных“ AlGaAs/GaAs-гетеробиполярных транзисторов с характерной толщиной базы 70-350 нм. Детально проанализированы особенности транспорта электронов в активной области транзисторов и оценено влияние эффекта всплеска скорости и диффузии квазибаллистических электронов на повышение радиационной стойкости транзисторов.
\end{abstract}

Ключевые слова: биполярные и гетеробиполярные транзисторы, кремний-на-сапфире, транспорт электронов, моделирование, радиационная стойкость.

DOI: $10.21883 /$ FTP.2019.10.48295.41

\section{1. Введение}

Современные технологии микроэлектроники позволяют разрабатывать интегральные схемы усилителей, генераторов и других аналоговых устройств как на традиционных объемных GaAs-эпитаксиальных структурах, так и на пленочных ионно-легированных Si-структурах типа „кремний-на-изоляторе“ (КНИ). Известно [1-4], что радиационная стойкость структур, изготовленных по технологии „кремний-на-изоляторе“, выше, чем у структур, выполненных на объемном кремнии. С другой стороны, радиационная стойкость Si-интегральных схем в целом ниже, чем у схем на основе GaAs, из-за применения в кремниевых схемах подзатворных и захороненных диэлектрических слоев, накапливающих связанный положительный заряд при $\gamma$-облучении. В связи с развитием технологии и конструкции перспективных транзисторов актуальным является сопоставление параметров новых активных элементов $\mathrm{Si}^{-}$и $\mathrm{GaAs-интегральных}$ схем - специальных биполярных и гетеробиполярных транзисторов с точки зрения их радиационной стойкости к $\gamma$ - и нейтронному облучению.

Традиционным подходом для создания структур GaAsгетеробиполярных транзисторов является молекулярнолучевая эпитаксия слоев эмиттера, базы и коллектора, так что конструкция транзистора является „вертикальной“, т. е. направление движения электронов от эмиттера к коллектору происходит по нормали к поверхности полупроводниковой структуры. При этом толщина базы современных гетеробиполярных транзисторов составля- ет десятки нанометров, что обусловливает проявление баллистических эффектов транспорта электронов. Это влияет на уровень радиационной стойкости таких транзисторов [1,2,5-7].

Особенностью изготовления интегральных схем на структурах КНИ является применение технологии ионного легирования для создания слоев эмиттера, базы и коллектора. При этом толщина приборного слоя кремния, который в КНИ структурах отсечен от кремниевой подложки слоем $\mathrm{SiO}_{2}$, обычно составляет $\sim 0.1-0.2$ мкм [3]. Из-за того что области пространственного заряда $p-n$-переходов эмиттера и коллектора имеют величину, большую, чем указанная толщина приборного слоя, изготовление традиционной „вертикальной“ конструкции транзистора затруднено. В таком случае применяют известную технологию и конструкцию BiCMOS, радиационная стойкость которой хорошо изучена [3]. Основным недостатком BiCMOS конструкции транзисторов является использование МДП-структуры в качестве эмиттера в транзисторе, который по принципу работы аналогичен классическому „вертикальному“ биполярному транзистору. Облучение $\gamma$-квантами приводит к генерации электронно-дырочных пар, причем электроны покидают диэлектрический слой из-за действия электрического поля, а дырки захватываются ловушками и образуют положительный заряд в диэлектрике, который существенно изменяет напряжение отсечки транзисторов при уровнях облучения $10^{4}-10^{5}$ рад [1-3].

В работе [4] предложена одна из возможных конструкций радиочастотных и СВЧ КНИ биполярных 
транзисторов, позволяющая организовать латеральный транспорт электронов от эмиттера к коллектору, а в качестве эмиттера использовать $n-p$-переход. При этом характерная толщина базы может составлять 100 нм и менее, что позволяет реализовать квазибаллистический перенос электронов через базу. Радиационная стойкость латеральных транзисторов на структурах КНИ детально не исследована. Поэтому в данной работе сопоставляется влияние $\gamma$-нейтронного излучения на $\mathrm{Si}$ и GaAs-транзисторы, которые применяются для изготовления радиочастотных и СВЧ интегральных схем.

\section{2. Исследуемые транзисторы}

Исследуемый $\mathrm{GaAs} / \mathrm{AlGaAs-гетеробиполярный}$ $n-p-n$-транзистор был изготовлен в АО «НПП „Салют“» (Нижний Новгород). Использовались эпитаксиальные структуры с различным составом, типом проводимости и легированием слоев, которые были выращены методом молекулярно-лучевой эпитаксии на полуизолирующей подложке GaAs-ориентации (001) в ФТИ им. А.Ф. Иоффе (Санкт-Петербург). Толщина слоя базы составляла 70 нм, концентрация акцепторов в базе $\sim 10^{19} \mathrm{~cm}^{-3}$, концентрация доноров в слабо легированной части коллектора $\sim 10^{16} \mathrm{~cm}^{-3}$. С целью создания контактов базы травление до базового слоя проводилось в аммиачном травителе. Глубина травления определялась на оптическом профилометре. Для площади эмиттеpa $11 \times 4$ мкм $^{2}$ было достигнуто максимальное усиление по постоянному току $\beta=70$, граничная частота усиления составила 58 ГГц. Увеличение площади эмиттера до значения $33 \times 5$ мкм $^{2}$ снизило предельную частоту до величины около 10 ГГц, что сопоставимо с кремниевыми транзисторами и позволило проводить сопоставление их радиационной стойкости для условий работы в одном и том же частотном диапазоне порядка единиц гигагерц.

C GaAs-гетеробиполярным транзистором сопоставлялся биполярный транзистор $n-p-n-\mathrm{Si}$ оригинальной „латеральной“ конструкции на структуре „кремний-наизоляторе“. Расположение активных областей эмиттера, базы и коллектора таково, что движение электронов от эмиттера к коллектору проходило параллельно поверхности полупроводниковой структуры. Это позволило разместить транзистор в 200-нм приборном слое кремния структуры „кремний-на-изоляторе“.

Исходную пластину „кремния-на-изоляторе“ легировали с помощью метода ионной имплантации по маске шириной 0.35 мкм. Концентрация легирующей примеси составила в слоях: $n^{+}-1 \cdot 10^{19} \mathrm{~cm}^{-3}, p-2 \cdot 10^{16} \mathrm{~cm}^{-3}$, $n^{-}-10^{16} \mathrm{~cm}^{-3}$. Используя традиционный подход, рассчитано влияние длительности отжига на диффузию примеси при трех разных температурах постимплантационной активации примеси: 950, $1000,1050^{\circ} \mathrm{C}$. На рис. 1 приведены профили распределения бора и фосфора после отжига. Видно, что за счет диффузии примесей возможно снижение толщины базы до значений 200 нм и

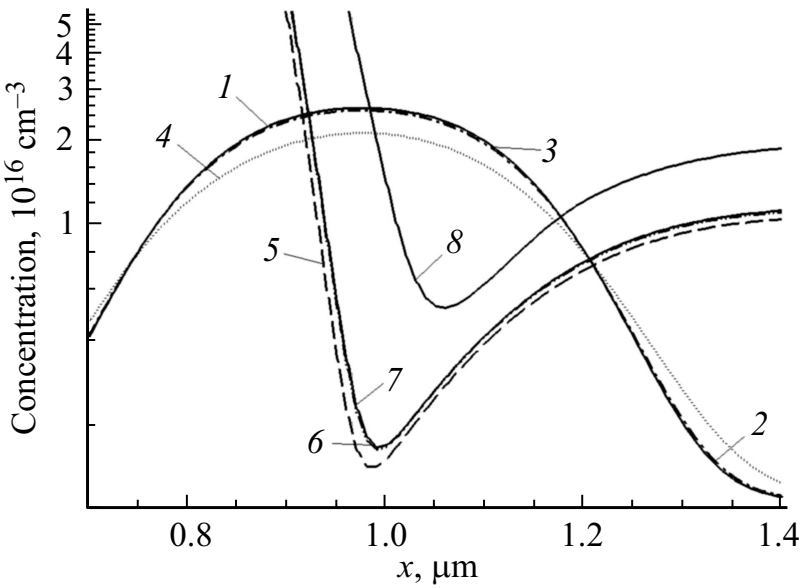

Рис. 1. Расчетные профили концентраций примеси в латеральной КНИ кремниевой структуре $n^{+}-p-n$, легированной по маске, шириной 0.35 мкм. Примесь активировалась при разных условиях: $1-$ бор, $T=950^{\circ} \mathrm{C}, 30 \mathrm{c} ; 2-$ бор, $T=950^{\circ} \mathrm{C}$, 300 c; $3-$ бор, $T=1050^{\circ} \mathrm{C}, 30 \mathrm{c} ; 4-6 o p, T=1050^{\circ} \mathrm{C}, 300 \mathrm{c}$; 5 - фосфор, $T=950^{\circ} \mathrm{C}, 30 \mathrm{c} ; 6-$ фосфор, $T=950^{\circ} \mathrm{C}, 300 \mathrm{c}$; $7-$ фосфор, $T=1050^{\circ} \mathrm{C}, 300 \mathrm{c} ; 8-$ фосфор, $T=1050^{\circ} \mathrm{C}$, $300 \mathrm{c}$.

менее. Полученные данные в дальнейшем были использованы в качестве исходных для расчетов параметров транзисторов до и после $\gamma$-нейтронного облучения.

\section{3. Методика моделирования и результаты расчетов}

Рассмотрена схема включения транзистора с общим эмиттером. Напряжение, приложенное к базе, варьировалось в пределах 0-0.8 В, а напряжение, приложенное к коллектору, варьировалось в пределах 0.6-10 В.

Численное моделирование проводилось при помощи локально-равновесной диффузионно-дрейфовой модели [5], локально-неравновесной диффузионно-дрейфовой модели [6], квазигидродинамической модели [7,8] и метода Монте-Карло [6]. Аналитический расчет проводился с учетом эффектов „тонкой базы“: переходных ионизационных процессов [9], деградации характеристик [10] и разогрева электронного газа [11] при радиационном воздействии.

Радиационное воздействие учитывалось путем изменения электрофизических параметров полупроводниковой структуры транзистора - концентрации носителей заряда, их подвижности, коэффициента диффузии, времени жизни и дрейфовой скорости насыщения, времен релаксации энергии и импульса $[1,2,9]$. Также вводился связанный положительный заряд в диэлектрические слои на границе с рабочим слоем кремния. Уровень заряда был пропорционален дозе $\gamma$-облучения [1-3].

Оценка условий баллистического и диффузионного переноса носителей заряда через базу биполярных 
Оценка условий баллистического и диффузионного переноса носителей заряда через базу биполярных транзисторов на основе $\mathrm{Si}$ и $\mathrm{GaAs}$ при нормальной температуре [11 ${ }^{*}$

\begin{tabular}{c|c|c}
\hline & $\mathrm{Si}$ & $\mathrm{GaAs}$ \\
\hline$L_{f}=v_{T} \tau_{p}, \mathrm{HM}$ & 16 & 34 \\
$L_{D}=D / v_{T}, \mathrm{HM}$ & 150 & 320
\end{tabular}

Примечание. ${ }^{*} L_{f}-$ средняя длина свободного пробега, $v_{T}-$ тепловая скорость носителей, $\tau_{p}-$ среднее время пролета носителей между столкновениями, $L_{D}-$ средняя длина диффузии, $D-$ коэффициент диффузии.

транзисторов на основе $\mathrm{Si}$ и GaAs проведена в работе $[12,13]$ и представлена в таблице. Таким образом, движение носителей заряда в рассматриваемом

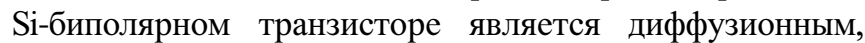
в GaAs-гетеробиполярном транзисторе - смешанным диффузионно-баллистическим.

Результаты расчетов изменения коэффициента усиления транзисторов при воздействии дефектообразующих излучений приведены на рис. 2 и 3. С уменьшением толщины базы транзисторов влияние диффузионной компоненты на перенос неосновных носителей заряда уменьшается, движение носителей становится сначала квазибаллистическим, а затем преимущественно баллистическим. Это обусловливает снижение темпов деградации характеристик субмикронных транзисторов при воздействии дефектообразующих излучений, что обусловливает их более высокую радиационную стойкость. Отметим, что уменьшение толщины базы требует

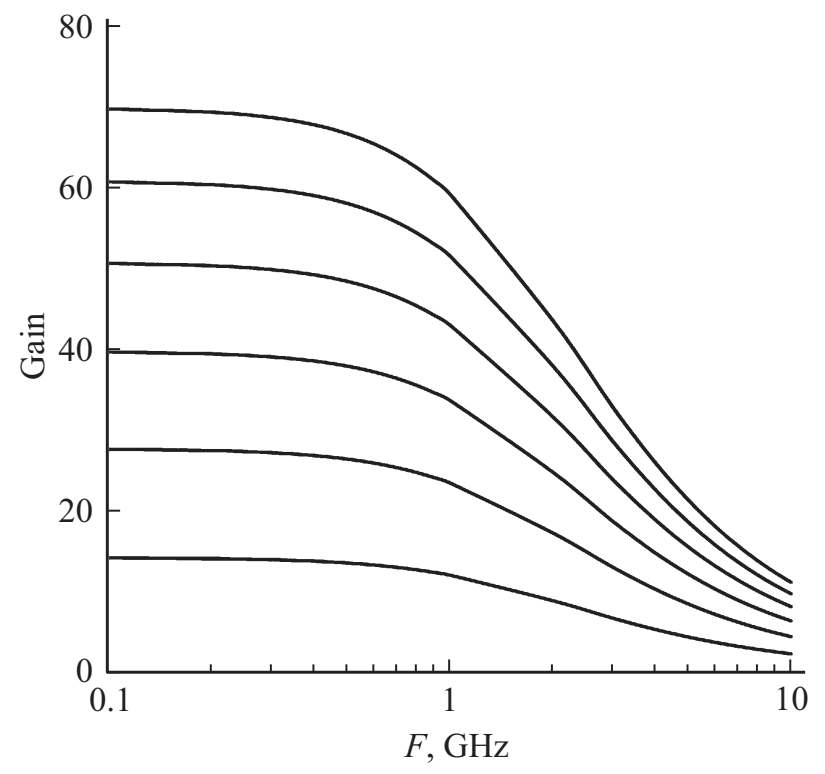

Рис. 2. Расчетное изменение коэффициента усиления $\mathrm{Si}$-биполярного транзистора при воздействии $\gamma$-нейтронного излучения. Верхняя кривая - транзистор до облучения, нижние - облучение уровнями $10^{5}$ рад и $10^{14} \mathrm{~cm}^{-2}, 2 \cdot 10^{5}$ рад и $2 \cdot 10^{14} \mathrm{~cm}^{-2}, 3 \cdot 10^{5}$ рад и $3 \cdot 10^{14} \mathrm{~cm}^{-2}$ и т.д., чем ниже, тем больше уровень облучения.

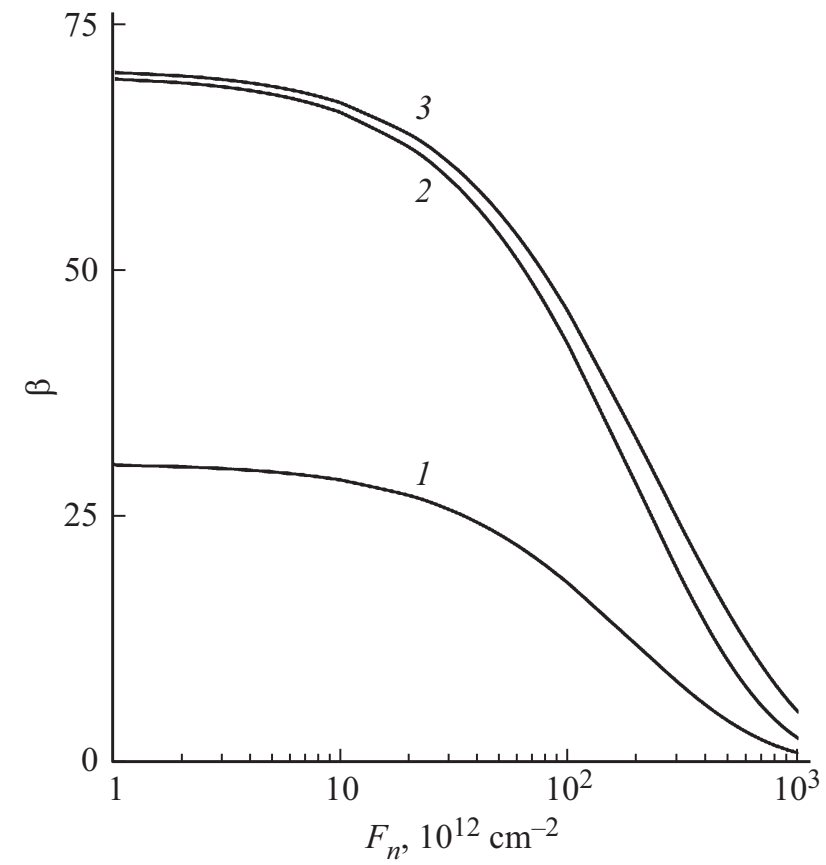

Рис. 3. Расчетное изменение коэффициента усиления по постоянному току в зависимости от флюенса облучения: 1 - Si-биполярный транзистор с толщиной базы $350 \mathrm{HM;}$ 2 - Si-биполярный транзистор с толщиной базы 220 нм; 3 - GaAs-гетеробиполярный транзистор с толщиной базы 70 нм.

увеличения концентрации легирующей примеси в ней для предотвращения смыкания областей пространственного заряда эмиттерного и коллекторного переходов и прокола базы, что на микроскопическом уровне ведет к снижению средней длины пробега носителей заряда между рассеяниями. С другой стороны, с уменьшением толщины базы растет вклад горячих носителей заряда, обусловленный надбарьерной инжекцией и имеющий направленную компоненту скорости. Поэтому на макроскопическом уровне коэффициент усиления субмикронных транзисторов растет с уменьшением толщины базы, а его деградация замедляется в 1.5-2 раза при воздействии дефектообразующих излучений для толщины базы 90-150нм. Кроме того, увеличение уровня легирования базы подавляет возникновение паразитного канала утечки вдоль границы раздела $\mathrm{Si} / \mathrm{SiO}_{2}$, связанного с накоплением неподвижных положительных зарядов в диэлектрическом слое из-за воздействия $\gamma$-квантов.

\section{4. Заключение}

Результаты моделирования транспорта электронов в активной области транзисторов показали, что важным является учет квазибаллистического транспорта электронов через базу транзисторов - необходимо учитывать как диффузионную, так и дрейфовую компоненту токов носителей заряда, для чего необходимо применять 
специальный подход [6]. Последнее крайне актуально для характерных толщин базы менее 100 нм. Сравнение экспериментальных и теоретически рассчитанных параметров транзисторов до облучения показало адекватность предложенных подходов учета особенностей транспорта электронов. Сопоставление результатов расчета параметров как $\mathrm{Si}$-, так и $\mathrm{GaAs}$-транзисторов до и после $\gamma$-нейтронного облучения показало, что уровень радиационной стойкости транзисторов сопоставим, а его значение выше, чем $10^{14} \mathrm{~cm}^{-2}$ и 0.1 Мрад. Таким образом радиационная стойкость латеральных биполярных транзисторов на структурах типа „кремний-на-изоляторе“ может достигать уровней присущих традиционным СВЧ транзисторам.

Дальнейшее уменьшение технологических норм должно увеличивать стойкость биполярных транзисторов на структурах „кремний-на-изоляторе“ к действию дефектообразующих излучений. При этом, как показано в работе [12], значительную роль начинает играть неоднородность распределения радиационных дефектов на микроскопическом уровне, так как толщина базы транзистора становится сравнимой с размерами области разупорядочения, формируемой первичным атомом отдачи при воздействии потока нейтронов. Это может привести к радиационно-индуцированному проколу базы с последующим катастрофическим отказом. Таким образом, с уменьшением технологических норм происходит изменение динамики деградации характеристик полупроводниковых структур: от постепенного ухудшения к скачкообразному изменению с ростом дозы/флюенса излучения, аналогичному одиночным событиям при воздействии тяжелых заряженных частиц космического пространства.

\section{Финансирование работы}

Исследование поддержано грантом Российского научного фонда (проект № 18-13-00066).

\section{Благодарности}

Авторы благодарят Д.И. Дюкова и А.Г. Фефелова за ценные замечания и рекомендации.

\section{Конфликт интересов}

Авторы заявляют, что у них нет конфликта интересов.

\section{Список литературы}

[1] Е.А. Ладыгин. Действие проникающей радиации на изделия электронной техники (М., Сов. радио, 1980).

[2] Ф.П. Коршунов, Ю.В. Богатырев, В.А. Вавилов. Воздействие радиации на интегральные микросхемы (Минск, Наука и техника, 1986).

[3] L. Ratti, V. Speziali. Proc IEEE Topical Meeting on Silicon Monolithic Integrated Circuits in RF Systems (SiRF) (Atlanta, GA, USA, Sep. 18-20, 2006) p. 251.
[4] I-Sh.M. Sun, W.T. Ng, H. Mochizuki, K. Kanekiyo, T. Kobayashi, M. Toita, H. Imai, A. Ishikawa, S. Tamura, K. Takasuka. Proc IEEE Topical Meeting on Silicon Monolithic Integrated Circuits in RF Systems (SiRF) (San Diego, USA, Jan. 8-10, 2006) p. 50.

[5] В.К. Киселев, С.В. Оболенский, А.С. Пузанов, А.В. Скупов. Журн. радиоэлектроники, 17 (2), 10 (2014).

[6] А.С. Пузанов, С.В. Оболенский, В.А. Козлов. ФТП, 52 (11), 1295 (2018).

[7] А.С. Пузанов, С.В. Оболенский. Микроэлектроника, $38(1), 64$ (2009).

[8] А.С. Пузанов, С.В. Оболенский. Микроэлектроника, 41 (4), 304 (2012).

[9] А.С. Пузанов, С.В. Оболенский. Вопросы атомной науки и техники. Сер. Физика радиационного воздействия на радиоэлектронную аппаратуру, вып. 4, 5 (2012).

[10] В.К. Киселев, С.В. Оболенский, А.С. Пузанов. Вестн. ННГУ. Сер. Радиофизика, вып. 2, 56 (2013).

[11] А.С. Пузанов. Вестн. ННГУ. Сер. Физика твердого тела, вып. 2, 88 (2014).

[12] А.С. Пузанов, С.В. Оболенский, В.А. Козлов. ФТП, 49 (1), 71 (2015).

[13] А.С. Пузанов, С.В. Оболенский, В.А. Козлов. ФТП, 50(12), 1706 (2016).

Редактор А.Н. Смирнов

\section{A comparison of radiation resistance of promising bipolar and heterobipolar transistors}

\author{
T.A. Shobolova ${ }^{1}$, A.V. Korotkov ${ }^{1}$, E.V. Petraykova ${ }^{1}$, \\ A.V. Lipatnikov' ${ }^{1}$, A.S. Puzanov' ${ }^{1}$, S.V. Obolensky ${ }^{1}$, \\ V.A. Kozlov ${ }^{2}$ \\ ${ }^{1}$ Lobachevsky State University of Nizhny Novgorod, \\ 603950 Nizhny Novgorod, Russia \\ ${ }^{2}$ Institute for Physics of Microstructures, \\ Russian Academy of Sciences, \\ 603087 Nizhny Novgorod, Russia
}

Abstract Approaches to solving the problem of creating effective radio-frequency and microwave $(0.10) \mathrm{GHz}$ bipolar and heterobipolar transistors that could be used as active elements of modern $\mathrm{Si}$ (on the structures of „silicon on insulator“) and GaAs integrated circuits designed for special-purpose equipment, to which the requirements of increased radiation resistance. The radiation resistance of promising „horizontal“ Si bipolar and vertical $\mathrm{AlGaAs} / \mathrm{GaAs}$ heterobipolar transistors with a characteristic base thickness of $70-350 \mathrm{~nm}$ is compared. The features of electron transport in the active region of transistors were analyzed and the influence of the effect of a burst of velocity and diffusion of quasiballistic electrons on the increase in the radiation resistance of transistors was estimated. 